\title{
The Effect of Visual-Sport Specific Exercise on Shooting Skill Performance in Football Players
}

\author{
Azzam Afshar* \\ Master of Motor Behavior, Faculty of Physical Education and Sport Sciences, Iran \\ *Corresponding author: Azzam Afshar, Master of Motor Behavior, Faculty of Physical Education and Sport Sciences, Iran
}

\section{ARTICLE INFO}

Received: 湠 February 06, 2019

Published: March 05, 2019

Citation: Azzam Afshar. The Effect of Visual-Sport Specific Exercise on Shooting Skill Performance in Football Players. Biomed J Sci \& Tech Res 15(3)2019. BJSTR. MS.ID.002714.

Keywords: Practice; Athletic Vision; Performance; Soccer; Shoot; Girl

\begin{abstract}
Purpose: The purpose of this study was to determine the effect of sport-sighted exercises on the performance of shooting skills of footballer girls in Karaj.

Method: The research method was quasi-experimental study the subjects were assigned into the experimental and control groups, with pre-test and post-test design. The statistical population of this study was all girls of football school in Alborz province in 1397. In this study, Among the community, 45 athletes with an average age of 19 years were selected from club clubs in Alborz province (Karaj city) with less than 1 month of education as an available and targeted sample The research tool was based on Raven and Gibor's vision exercises (1981), a researcher-made exercise (colored gates, colored caissons). Specific vision group training and athletic training group performed the exercises for 2 weeks ( 3 sessions per week and 12 minutes each session). The covariance analysis and Bonferron's post hoc test were used to analyze the data.
\end{abstract}

Results: The results of the study showed that there was a significant difference between the average corrected shoot performance of soccer girls in the field of visual training, athletic vision and control $(\mathrm{p}=0.000)$. In fact, visual training did not have a significant effect on the performance of soccer girls shots $(\mathrm{P}=0.003)$, but sports-visual exercises improved their shooting skills ( $\mathrm{P}=0.002)$, as well as exercise-based exercises compared to exercises Vision led to a significant improvement in the skill of the soccer girls shots $(\mathrm{P}=0.005)$.

Conclusion: sports-based sports exercises could be more beneficial to improve the performance of soccer girl's shots.

\section{Introduction}

One of the key issues with effective design of learning and practice situations is the information resources used to control motor skills; For example, recognizing the sources of information used by skilled people to control movements can help guide the attention of athletes to these resources. Vision is one of the main sensory systems involved in the implementation of many sports skills. This system has a direct connection with brain sensory centers [1]. These centers are responsible for controlling the position of the body in space, which is especially important during physical activity and exercise; however, despite its fundamental role, during the design of training programs, its importance is less important for educators and athletes [2]. This may be due to the limited time available for training or the lack of research to demonstrate the benefits of visual training [3]. Although visual exercises in sports are not new concepts; but these exercises have done more in laboratories and clinical environments that cost a lot to the athlete [2]. On the other hand, the results of laboratory research are most widely used in clinical conditions and their application in sporting environments has not yet reached the stage of implementation [4]. In general, research shows that athletes carry out specific exercises to enhance their visual skills and increase their decision-making skills, which they have a much better performance than beginners [5].

Therefore, identifying the mechanisms involved in this better performance can help researchers to provide more accurate and applied planning for the purpose of talent detection and educating athletes [6]. Generally, it has been accepted that skilled performers 
do not have vision skills, rather, the cognitive foundations of the advances that enable them to receive perceptual information more efficiently than their counterparts who are less skilled [7]. Wood and Abernethy (2001) showed that some visual skills (which he called "hardware skills") were more intrinsic and did not respond to visual training exercises. While software skills are more adventitious and affected by visual exercises [3]. Ludeke \& Ferreira (2003) declare that visual hardware skills include perspicuity, matching, and profound perception that are more intrinsic and software or cognitive components include vision perception, vision focus, visual response time, peripheral awareness and visualization [8]. These skills are more influenced by practice and experience and can be improved and upgraded. Regardless of whether visual skills are practicable or not, research suggests that visual exercises can develop brain-related visual areas such as visual memory, Background shape perception, and directional.

This helps the athlete to be able to use them well in their sport field [1]. In many skills, if athletes do not pay attention to important symptoms at the start of their work, their chances of success in the performance will be greatly reduced. Skills such as determining the place of Sending pass in football or deciding what kind of move a defender should do in basketball or football depends entirely on the player's attention to the visual symptoms of action [9]. To participate in a competitive sport, such as cricket and football, one of the important aspects that every coachman must always remember is to achieve the best possible performance of the entire body, including the visual system. The influence of the player's ability to act quickly and correctly depends on how effective the visual system can process the information. Effective visual skills are one of the most important assets that a player can have. When we consider the selected sport that the athlete is participating in, the odds are those visual skills that play a very important role in that particular activity [10]. Several researchers such as Rio, Maki and Fuber (1986) have stated that when there are vision, individuals rely on it as the main source of information, even if the information is not accurate enough to lead to successful performance.

To retrieve information from the external environment, we strongly rely on our vision system. There is no doubt that athletic performance is related to perceptual cognitive skills as well as motor and physical abilities, over the past years, perceptual skills have received significant research interest in sports, one of the main differences between good and elite athletes is that elite athletes move their eyes more quickly and more adequately [11]. Although evidence of the effectiveness of visual exercises is available on sports performances [12]; But there are some contradictory findings in this regard; For example, Wood and Abernethy studies $(2001,1997)$ showed that the utility of these programs when exercising with physical exercises is not more than physical exercise [3,13]. In this regard, fallen (1396) the effect of visual and skill training on visual and performance skills, retention and transmission of badminton short backhand service [14]; Farsi, Abdoli and Basiri (1393) The
Effect of Vision and Skills Training on forhand learning in tennis on the Table [15]; Azimzadeh, Ghasemi and Gholami (1394) The Effect of a Selected vision Exercise Program and Two Tennis Skills on the Table [1]; Hopwood, Mann, Farrow and Nielsen (2011) The Effect of Perceived Vision Exercise on the Performance of Skilled Cricket Players [16]; Veale, Pearce, Koehn \& Carlson (2008) The effect of vision program on visual skills of professional football players [17], Abernethy and Wood (2001) examined the effect of generalized vision training on the performance of two groups of athletes in rocket science [3].

Regarding the backgrounds, most research on rocket sports and Adult male professional samples has been carried out and fewer research has been done in the field of football in the country, due to the importance of visual information on performance and specifically on the athlete's female society. Because football is a popular sport and a political, cultural, social and sporting event and today, the success of football teams is a measure of the development of a country, Therefore, research in its various domains, in particular psychological and psychoanalysis, can contribute to the development of this field and its strategies should be used by players, coaches, etc. Doing research in this regard could be the reason for future research. Therefore, in order to study the effectiveness of visual and physical exercises on the performance of the sport, especially the women's football field that has recently gained great honors, it seems necessary to provide valuable information, In this regard, a research titled "Effect of sport-vision exercises on the performance of shooting skill of soccer girls in Karaj" Was performed.

\section{Methodology}

\section{Research Method}

The method of this research was semi experimental with the applied nature and random sampling of the subjects in the experimental and control groups, along with pre-test and post-test, and the data was collected by field.

\section{Society and Statistical Sample}

The statistical population of this study was all girls of football school in Alborz province in 1397. From the present society, 45 female footballers with an average age of 19 years were selected from club teams in Alborz province (Karaj) with less than 1 month of training as an accessible and purposeful sample and randomly divided into 3 groups ( 2 experimental groups and 1 group Control). The criteria for participation in this study included physical and mental health (according to health records), family, activity level, physical characteristics, parental satisfaction, and willingness and volunteering of the participants themselves.

\section{Research Tool}

In the present study, the standard futsal hall, ball, goalkeeper, standard stopwatch, More- Christian Shot test, Revien \& Gabor 
vision exercises (1981), researcher-made sports vision exercises (colored goalkeepers, colored caissons) were used as a tool.

\section{Researcher-Made Sports Vision Exercises}

The Exercises sports vision consisted of four colored goalkeeper, each randomly lit for 3 seconds, shot at the futsal goal, according to colored caissons, for visual acuity and shoot. These exercises were considered for 12 minutes. In order to avoid differences in instructional guidelines and feedback, an AFC official football coach was used in experimental groups. The formal validity of this exercise was confirmed by the $3 \mathrm{AFC}$ official football coaches and three faculty members in the field of physical education and sports science (Table 1 ).

Table 1: Description of researcher-made visual-sport exercises.

\begin{tabular}{|c|c|c|c|}
\hline Exercise & Tool & Description of Exercise & Targets \\
\hline 1 & $\begin{array}{l}3 \text { color barriers - balls to } \\
\text { the number of players - one } \\
\text { gate }\end{array}$ & $\begin{array}{l}\text { The player begins to move from the start point with the ball, then he } \\
\text { shoots into the penalty area in the designated obstacle by the coach. }\end{array}$ & $\begin{array}{l}\text { Increasing sharpness - Increasing } \\
\text { decision speed - Increasing the } \\
\text { accuracy of the ball hit }\end{array}$ \\
\hline 2 & $\begin{array}{l}3 \text { barriers whit different } \\
\text { colors- ball- gate }\end{array}$ & $\begin{array}{l}\text { Players from the back of the obstacle, shoot the colored obstacles } \\
\text { inside the goal, which are determined by the coach. }\end{array}$ & $\begin{array}{l}\text { reinforcement of sharpness-rein- } \\
\text { forcement of puncture accuracy }\end{array}$ \\
\hline 3 & 2 ball- 2 players & $\begin{array}{l}\text { The player in possession of the ball must throw the ball simultane- } \\
\text { ously with the hand and foot for the opponent, and the opponent also } \\
\text { receives both balls simultaneously. }\end{array}$ & $\begin{array}{l}\text { Environmental awareness - Nerve } \\
\text { and muscle coordination - Pre- } \\
\text { cision in the pass-Precision in } \\
\text { receiving pass }\end{array}$ \\
\hline 4 & $\begin{array}{l}\text { balls to the number of } \\
\text { players- small gate }\end{array}$ & $\begin{array}{l}\text { Players place their balls in the marked areas and shoot to the marked } \\
\text { areas of the goal. The next time the players changed their place to } \\
\text { shoot from different locations. }\end{array}$ & $\begin{array}{l}\text { Increased accuracy in impact - } \\
\text { Increases sharpness }\end{array}$ \\
\hline 5 & $\begin{array}{l}3 \text { different cones in } \\
\text { different colors - balls in } \\
\text { the number of players - } 3 \\
\text { different flags in different } \\
\text { colors - one gate }\end{array}$ & $\begin{array}{l}\text { The players are divided into } 3 \text { groups, then each group stands behind } \\
\text { the barrier with a marked color, and the player of each group shoots } \\
\text { by the coach to see the color of the flag. }\end{array}$ & $\begin{array}{l}\text { Precision in Shot-Visually involving } \\
\text {-Speed in Decision-making }\end{array}$ \\
\hline 6 & 11 players- 11 hats- 6 balls & $\begin{array}{c}11 \text { players are divided into two groups of } 5 \text { and } 6 \text { each, and each } 11 \\
\text { players have hats during the training. Group } 6 \text { has balls and } 5 \text { others } \\
\text { without balls. The players begin to move in the designated area, then } \\
\text { with the coach's whistle, } 6 \text { players holding the ball should give the ball } \\
\text { to the players without a ball. A player who can't pass the ball gets a } \\
\text { negative score. }\end{array}$ & $\begin{array}{l}\text { Environmental awareness- Hold } \\
\text { your head up- See the team player } \\
\text {-fast in pass-accurate pass. }\end{array}$ \\
\hline 7 & $\begin{array}{l}4 \text { colored gates - } 2 \text { colored } \\
\text { barriers - } 6 \text { players - balls }\end{array}$ & $\begin{array}{l}\text { On the pitch two teams are with } 3 \text { players. In each pitch, two gates } \\
\text { are in different colors. The players start playing with the whistle of } \\
\text { the coach, and when they enter the opponent's ground, they must hit } \\
\text { the gate that the coach specifies. As long as there is a chance to hit the } \\
\text { goal, the ball does not leave the opponent's ground. }\end{array}$ & $\begin{array}{l}\text { Increasing the speed of the game } \\
\text { - Enhancing environmental aware- } \\
\text { ness - game development - Transfer } \\
\text { game- counter attack - Accuracy on } \\
\text { impact }\end{array}$ \\
\hline 8 & 4 small gates- 6 players & $\begin{array}{l}\text { The player inside the circle in the middle of the ground moves whit } \\
\text { the ball, then the coach announces the color of the goal and the player } \\
\text { must enter the goal in the shortest possible time. The coach stands } \\
\text { with six balls next to the ground and passes the ball every time the } \\
\text { ball goes out. }\end{array}$ & Accuracy Pass-Speed Pass \\
\hline
\end{tabular}

\section{Revien \& Gabor Exercises}

A visual instruction is used to perform visual training exercises that include:

A. Exercise for stimulation of light: In this exercise, a manual flashlight turns on and off to allow the central cells of the retina to enhance the light and darkness, and ultimately improve the sharpness.

B. Snail rotation workout: In this exercise, the person looks for a rotating spiral for a long time. This creates an illusion of increasing size in seeing objects. In this way, the perceptual system of the athlete becomes familiar with this illusion, and this illusion is not temporary in sporting movements that require head rotation. In this way, the perceptual system of the athlete becomes familiar with this illusion, and this illusion is not temporary in sporting movements that require head rotation.

C. Twine attached to the ball workout: In this exercise, you must move your kenning from the ball on the twine to the other ball (at approximately 3 meters) and vice versa. This exercise improves adaptive ease and convergence of eyes skills.

D. Practice with swing balls: Participants should follow a fluctuating ball in the condition of their heads are immobile. 
This exercise improves the Sakadian fluent motion of the eyes.

E. Chasing a ball with a finger: In this exercise, you should follow the swing ball with your fingertip. This exercise can improve the coordination of the athlete's eyes and hands.

F. Practice rotating colors: In this exercise, there is a round plate with different black spots (in terms of shape and size) on it, rotating at different speeds. The athlete should follow the points on the screen. This exercise improves environmental awareness.

G. Practice the ball in the carton: In this exercise, there is a cardboard box with 6 to 12 colored orbs. In the middle of the cardboard there is a black spot that the participants must, while setting their eyes on it, move the orbs in the card with their fingers on specific paths.

H. Back and forth workouts: In this exercise, which is used to improve visual memory, there are between 50 and 100 cards, in the middle of each one a black circle and on two sides of the circle, two multi-digit number are spaced from the same distance, but their spacing varies in different cards. As the cards move quickly to the examiner's hands, participants must read the numbers on the cards. Revien and Gabor (1981) say that this exercise improves the speed of assessment and peripheral vision.

I. Practice pulling the rope: An 8-meter rope is connected to two sides of the wall at a distance of 4 meters from the participant so that the participant can capture both ends of the head with two hands. The purpose of this exercise is to insert colored orbs in each of the ropes, so that they are spaced equal. This practice improves perception of the depth of athletes. Before and after the visual training, the participants performed warm-up and chill exercises in accordance with the Revien and Gabor Practice Guide (1981).

\section{More Christian's Shoot Skill}

This standard test is characterized by a distance of 120 centimeters away from the goalkeepers. Then they are divided into two circles of 120 centimeters in diameter, and in total there are 4 identical circles on each side of the gate. From a distance of 16 meters in four stages, each stage, four shoots are shot. For points to score, for example, if a player wants to shoot on the right and the top of the goal and the shoot to hit the same place, 10 points and if the shoot is lowered to the bottom of the goal, 4 points will be awarded. The balls placed on the ground will not receive points. The final score was 16 times. So far no specific norm has been proposed for it, and in Iran this test has been used repeatedly in various researches [18].

\section{Data Collection Method}

First, after receiving the reference, coordination with the managers and coaches of the selected football clubs of Alborz province (Karaj) was carried out. Then, 45 female soccer players (1 month from the date of registration and familiar with the basic skills) with a mean age of 19 years were volunteered to participate in the study and randomly divided into 3 groups ( 2 experimental and 1 control group). The generalities of the research process and the purpose were fully explained to the participants, and they were assured that all information would be kept confidential and would not be available to anyone. Then all the participants completed the consent form of the participation in the research and were present with full satisfaction in the research. Researchers have provided the best possible environmental conditions for participation in the research to the extent possible and for the participants to meet all the ethical and value aspects of the research. The participants were also given the opportunity to withdraw at any stage of the study for any reason. This research was conducted in three stages: pre-test, intervention, post-test.

Pre-Test Stage: The participants performed a 3rd attempt block as a pre-test from the first penalty point of the Futsal Ground before they started their training efforts. This was done while they did not do any visual training. At this stage, the scores of each participant were recorded.

Acquisition Stage: The acquisition stage consisted of eight sessions of practice, in which participants participated in each session according to the training table under the supervision of the trained coach. The visual training group received visual training sessions per week for 3 sessions ( 2 weeks and 12 minutes each session). Visual - Sport exercise group, 2 sessions per week (2 weeks each session and 12 minutes each) in each session, and 50 exercises made a shoot at the goal.

Post-Test Stage: 48 hours after the acquisition stage, the participants in the transfer test, which shoot 10 meters (second penalty in the futsal) from the goal and the points marked the goalkeeper were smaller. Each participant performed eight shoots (10 meters) with a superior leg. In this test, the accuracy of the shoot was examined. It should be noted that the control group did not perform any other physical and mental exercises, except for its usual exercises. The intervention involved 6 sessions, including 1 session of the pre-test and 8 sessions of the acquisition phase and 1 session of the post-test. It should be noted that to increase the accuracy of the results after the end of each week of training, samples were tested.

In this research, descriptive statistics were used. Inferential statistics, Shapiro-Wilk test was used to verify the validity of data, and covariance test and Bonferroni's post hoc test to test hypotheses at $95 \%$ confidence level using spss version 22 software.

Findings: Table 2, Mean and Performance Deviation Shooting skill of soccer girls show a group of visual-sports exercises, visual training and control in pre and post-test. 
Table 2: Describes the variable performance of soccer shoot skill.

\begin{tabular}{|c|c|c|c|c|c|c|}
\hline Performance & \multicolumn{2}{|c|}{ Control } & \multicolumn{2}{c|}{ Visual Training } & \multicolumn{2}{c|}{ Visual-sport training } \\
\hline & standard deviation & Average & standard deviation & Average & standard deviation & Average \\
\hline Pre-test & 8.1 & 9.73 & 8.7 & 11.11 & 7.6 & 19.4 \\
\hline Post test & 4.9 & 8.13 & 8.1 & 11.28 & 13.7 & 29.6 \\
\hline
\end{tabular}

The results showed: There is a significant difference between the average adjusted performance of shooters of soccer girls in the group of visual training, visual-sport and control exercises $(F(2,40)=9.36, P=0.000, r 2=0.31)$. The results of Bonferroni's post hoc test to determine the source of the differences showed that there is no significant difference between the averages corrected shoot performance of footballer girls in the visual training and control group ( $\mathrm{P}=0.300, \mathrm{BCa} 95 \% \mathrm{Cl}[-6.05,1.08])$ which means that visual exercises had no significant effect on the performance of soccer girls shots.

a) There is a significant difference between the average adjusted performance of shooters of soccer girls in visualsport and control exercises ( $\mathrm{P}=0.002$, BCa 95\% Cl $[8.2,3.9]$ ) which means that visual-sport exercises have improved the performance of soccer girls shots (Table 3).

Table 3: Shapiro-Wilk test results.

\begin{tabular}{|c|c|c|c|c|c|c|c|c|c|}
\hline \multirow{2}{*}{ Performance } & \multicolumn{4}{|c|}{ Visual-sport training } & \multicolumn{3}{c|}{ Visual training } & \multicolumn{3}{c|}{ control } \\
\cline { 2 - 10 } & Sig. & df & D & Sig. & df & D & Sig. & df & D \\
\hline Pre test & 0.077 & 15 & 0.894 & 0.251 & 14 & 0.924 & 0.100 & 15 & 0.901 \\
\hline Post test & 0.059 & 15 & 0.888 & 0.212 & 14 & 0.919 & 0.410 & 15 & 0.942 \\
\hline
\end{tabular}

b) There was a significant difference between the average adjusted performance of girls' soccer shootings in the group of visual training and visual-sport exercises $(\mathrm{P}=0.005$, BCa $95 \% \mathrm{Cl}[20.5,3.9])$ which means that sports-visual exercises compared with visual exercises resulted in a significant improvement in the skill of shooting soccer girls.

\section{Discussion and Conclusion}

The purpose of this study was to compare the effect of visualsport exercises on the performance of shoot skills on girl's football player in Karaj. Results of data analysis showed that visual exercises had no significant effect on the performance of soccer girl's shoot skill. But visual-sport exercises have improved the performance of the soccer girls shoot skill; also, visual-sport exercises compared to visual exercises led to a significant improvement in the soccer girls shoot skill. The results of this study were compared with Fallen (1396), Mahmoudi and Badami (1396), Farsi, Abdoli and Basiri (1393), Azimzadeh, Ghasemi and Gholami (1394), Shoja (1394), Hopwood, Mann, Farrow and Nielsen (2011) is the same [1,14$16,19,20]$; It is also consistent with the findings of Sherman (1980) and Balasaheb (2008) [12,21]. Sherman saw the effect of visualsport exercises on static visual acuity, dynamic visual acuity (depth perception), 3D vision, accurate mental imagery, eye movement and speed, environmental perception, and visualization in his research, He stated that all of these visual abilities are taught and improved with visual training [21]. In the study of the effect of visual training exercises on the performance of cricket throwing skills, found that six weeks of visual training affects deep athletic perception, as well as improving visual skills, including deep perception.

Balasaheb (2008) showed that if the visual exercises are designed in accordance with the requirements of the task, it can significantly increase the average impact on the ball in the cricket field, which results in this study is consistent with the present study [12]. Wilson \& Falchel (2009) stated that recovery from visual training exercises in eye movements, focusing skills, visual perceptual environments, and visual perceptual skills will be transferred to playground; therefore, it does help athletes to achieve optimal performance and reach the next level, regardless of how rigorously they were at the given level. They believe that in order to engage in a competitive sport such as cricket and football, one of the important aspects that every coachman must always remember is to achieve the best possible performance of the entire body, including the visual system. The effectiveness of the athlete's ability to act quickly and correctly depends on how effective the visual system can process the information. Effective visual skills are one of the most important tools an athlete can have. When we consider the selected sport that the athlete is taking on, chances are those visual skills that play a very important role in that particular activity [4]. Ayoubi, Mirinezhad and Fouladian (1396) state that skilled athletes are in better position than ordinary athletes in terms of depth perception. Vision is superior to perceptual-motor responses, which is superior to other sensory qualities. Effective motion behavior is entirely dependent on perception.

Perception of vision is also a problem that scientists have been focusing on for centuries. In order to effectively carry out many of the tasks in motion, accurate judgments about moving objects in space are necessary. On the other hand, this ability depends on vision perception. On the other hand, the ability to recognize the distance to have an effective performance plays a decisive role. In fact, deep-seated perception is a determining factor in all dynamic responsive exercises, which require the evaluation of appropriate visual factors that are important for understanding depth. In 
addition to speed assessment, reappraisal is also important in all of these sports because athletes need to process fast information to determine the best stimulated response. Therefore, according to the results, we can conclude that the performance of this study is similar to that of Ayoubi, Mirinezhad and Fouladian, due to both hereditary factors and their related exercises or their sport [10]. The results of this study showed that visual exercises had no significant effect on the performance of soccer girls shoot. It can be said that in order to enhance the visual skills of a sporting skill, the practice of that skill alone is not enough. Rather, exercising with visual training can bring the best results.

In this case, the perceived motor skills of the desired skill will be improved through specialized sporting exercises, and also visual training can be used as an auxiliary factor to develop the skill needs of the vision [1]. One of the reasons for lack of skill development in this group is probably a short training period, perhaps a 2-week practice, like the 4-week practice of Abernethy and Wood, could not significantly improve athletic and visual skills [3]. Therefore, we conclude that, in order to improve the performance of sports, especially the skill of football girls, to use visual exercises along with physical exercises, we should use it in combination and use it according to the results of this study, recommended to coaches, athletes, sports teachers, etc. It is suggested that in the future researches, the title of the present study should be more accurate and by measuring the visual, physical, perceptual factors related to performance, on women and men footballers of all levels (beginner, semi-professional and non-professional) in all age groups and, if possible, comparisons between disciplines The ball is made according to the same nature.

\section{Acknowledgment}

Special thanks to the sincere cooperation of the Alborz Provincial Football Association, the directors, supervisors and coaches of the selected football clubs in Karaj, and especially the football girls participating in this study.

\section{References}

1. Azimzadeh E, Ghasemi, Abdullah, Gholami, Amin (1394) The Effect of a Vocational and Athletic Exercise Program on Improving Visual Skills. Journal of Behavioral Movement. Institute of Nursing and Midwifery 7: 15-23.

2. Wilson TA, Falkel J (2004) Sports vision: training for better performance: Human Kinetics Champaign.

3. Abernethy B, Wood JM (2001) Do generalized visual training programmes for sport really work? An experimental investigation. Journal of Sports Sciences 19(3): 203-222.

4. Abdullah G, Maryam M, Meysam R, Amin G (2009) The Difference in Visual Skills Between Expert Versus Novice Soccer Referees. Journal of Human Kinetics 22(1): 15-20.
5. Williams AM, Ericsson KA (2005) Perceptual-cognitive expertise in sport: Some considerations when applying the expert performance approach. Human Movement Science 24(3): 283-307.

6. Williams AM, Hodges NJ, North JS, Barton G (2006) Perceiving Patterns of Play in Dynamic Sport Tasks: Investigating the Essential Information Underlying Skilled Performance. Perception 35(3): 317-332.

7. Vaeyens R, Lenoir M, Williams AM, Mazyn L, Philippaerts RM (2007) The Effects of Task Constraints on Visual Search Behavior and DecisionMaking Skill in Youth Soccer Players. Journal of Sport and Exercise Psychology 29(2): 147-169.

8. Ludeke A, Ferreira J (2003) The difference in visual skills between professional versus non-professional rugby players. The South African Optometrist 62(4): 150-158.

9. Magill RA, Anderson DI (2007) Motor learning and control: Concepts and applications. McGraw-Hill New York, USA.

10. Ayoubi S, Mirinezhad, Bibi Azzam, Fouladian, Javad. Comparison of athletic and non-athletic selective visual skills. Sports Psychology Magazine 1396: 37-48.

11. Memmert D, Simons DJ, Grimme T (2009) The relationship between visual attention and expertise in sports. Psychology of Sport and Exercise 10(1): 146-151.

12. Balasaheb T, Maman P, Sandhu J (2008) The impact of visual skills training program on batting performance in cricketers. Serbian journal of sports sciences 2(1): 17-23.

13. Wood JM, Abernethy B (1997) An assessment of the efficacy of sports vision training programs. Optom Vis Sci 74(8): 646-659.

14. Fallen S (1396) Six weekly visual and skill training on visual and performance skills, retention and transfer of Badminton's short backstreet service: Kharazmi University, Tehran, Iran.

15. Farsi AA, Behrouz, Basiri, Fahimeh (1393) Effect of visual and skill exercises on learning the effect of table tennis forehand. Journal of Behavioral and Sports Psychology, Shahid Beheshti University, pp. 9971005.

16. Hopwood MJ, Mann DL, Farrow D, Nielsen T (2011) Does VisualPerceptual Training Augment the Fielding Performance of Skilled Cricketers? International Journal of Sports Science \& Coaching 6(4): 523-535.

17. Veale JP, Pearce AJ, Koehn S, Carlson JS (2008) Performance and anthropometric characteristics of prospective elite junior Australian footballers: A case study in one junior team. Journal of Science and Medicine in Sport 11(2): 227-230.

18. Gharakhanlu R, Afzalpur, Mohammad Esmaeel (1381) Examine the current situation and Compilation of football scoring indicators. Research project of the Physical Education Institute of the Ministry of Science, Research and Technology, Tehran, Iran.

19. Shoja (1394) Examine the Effect of a Vision and Skill Practice on Improving Perceptual-Motor Ability in Athlete's Elderly Women. Master's degree dissertation Sport Sciences, University of Tehran, Tehran, Iran.

20. Mahmudi S, Badami, Rokhsareh (1396) Effect of visual training exercises on vision perception and motor skills in children aged 8 to 10 years old dyslexic. Journal of Cognitive Science p. 43-51.

21. Sherman A (1980) Overview of research information regarding vision and sports. Journal of the American Optometric Association 51(7): 661. 


\section{ISSN: 2574-1241}

DOI: 10.26717/BJSTR.2019.15.002714

Azzam Afshar. Biomed J Sci \& Tech Res

(C) (P) This work is licensed under Creative

Submission Link: https://biomedres.us/submit-manuscript.php

$\begin{array}{ll}\text { BIOMEDICAL } & \text { Assets of Publishing with us } \\ \text { RESEARCHES } & \text { Global archiving of articles } \\ \text { - Immediate, unrestricted online access }\end{array}$

